\title{
Helicobacter pylori increases proliferation of gastric epithelial cells
}

\author{
X G Fan, D Kelleher, X J Fan, H X Xia, P W N Keeling
}

\begin{abstract}
The direct and indirect effects of Helicobacter pylori on cell kinetics of gastric epithelial cell line AGS were investigated by flow cytometric analysis of Ki-67 positive cells and by MTT assay. Flow cytometric analysis of $\mathrm{Ki}-67$ positivity permits detection of cells that are in S-phase, whereas the MTT assay is a colometric measure of the number of viable cells. In the absence of added stimulants, 23.06 $(4 \cdot 88) \%$ mean (SD) of AGS cells were Ki-67 positive. When cells were preincubated in the presence of $H$ pylori, there was a significant increase in $\mathrm{Ki}-67$ positivity $(66.20(7 \cdot 89) \%, \quad \mathbf{p}<0.001)$. This increase was not seen in cells cultured in the presence of Campylobacter jejuni (24.63 (8.11)\% or Escherichia coli (21.66 (9.78) $\%$ ). Pre-incubation of AGS cells with supernatants from both $H$ pylori and mitogen activated peripheral blood lymphocytes also increased the per cent of cells that were Ki-67 positive (72.93 (8.68) and $69.96(12.35) \% ; p, 0.001)$ respectively. Similar results were also found in MTT assay. These data show that both $H$ pylori directly and the immune/inflammatory response to $H$ pylori indirectly can influence the rate of epithelial cell proliferation, suggesting this bacterium may be an initiating step in gastric carcinogenesis and an important co-carcinogenic factor in $\mathrm{H}$ pylori positive subjects.
\end{abstract}

(Gut 1996; 38: 19-22)

Keywords: Helicobacter pylori, cytokines, epithelial cell line, proliferation.

Helicobacter pylori has been implicated in the pathogenesis of gastric carcinoma as well as active chronic gastritis and peptic ulcer disease. ${ }^{1-3}$ Recently, it has been reported that $H$ pylori infection, as a risk factor for gastric cancer, is associated with proliferation of gastric epithelial cells in $H$ pylori positive hosts $^{45}$ and eradication of $H$ pylori significantly reduces gastric epithelial cell proliferation. ${ }^{46}$ Increased proliferation of epithelial cells is an important biomarker for increased risk of gastrointestinal adenocarcinoma. ${ }^{7}$ Demonstration of an association between $H$ pylori and gastric cancer would be of great importance, because it would indicate the possibility that eradication of the organism might prevent the disease in infected patients. Little is known, however, about the mechanism of the effect of $H$ pylori on epithelial cell kinetics and as to whether this is a direct or indirect effect. A study of the effect of $H$ pylori on gastric epithelial cell kinetics may provide clues to $H$ pylori associated gastric carcinogenesis.

Monoclonal antibody $\mathrm{Ki}-67$ reacts predominantly with a nuclear antigen expressed in S-phase of the cell cycle and is hence a marker for proliferating cells. ${ }^{89} \mathrm{Ki}-67$ has frequently been used to assess the number of cells in S-phase and hence inferentially the number of proliferating cells in tissue sections. These techniques may be modified for flow cytometry. Flow cytometry permits the objective quantification of the percentage of positive cells. ${ }^{8}$ Proliferative activity as determined by this antibody has been shown to be reliable in the assessment of the growth fraction in a wide variety of normal and malignant human tissues. $^{10}$ A colorimetric assay of 3-(4,5dimethylthiazol-2-yl)-2,5-diphenyl tetrazolium bromide (MTT) is a reliable colorimetric assay for evaluating cell proliferation. ${ }^{11}$ To better assess the role of $H$ pylori in gastric epithelial cell proliferation, direct and indirect effects of $H$ pylori on cell kinetics of gastric epithelial cell line AGS were investigated using flow cytometric analysis of $\mathrm{Ki}-67$ positive cells and colorimetric MTT assay in our study. The aim of this study, therefore, was to find out if $H$ pylori directly or cytokines produced by lymphocytes exposed to $H$ pylori could influence the rate of proliferation of gastric epithelial cells.

\section{Methods}

\section{Bacterium preparations}

$H$ pylori preparation was made by sonicating a mixture of $H$ pylori bacterial cultures obtained from six patients (four duodenal ulcer and two gastritis alone) on ice using six $\times 15$ seconds, 100 watt pulses, with 30 seconds cooling intervals followed by irradiation at $40 \mathrm{~Gy}$ to sterilise the preparation. It was then washed with phosphate buffered saline (PBS) and stored at $-20^{\circ} \mathrm{C} .^{12}$ Campylobacter jejuni and Escherichia coli (NCTC 8007) preparations were made by the same procedures described above.

\section{Cytokine rich supernatants}

Cytokine rich supernatants were prepared by co-culturing peripheral blood lymphocytes from healthy volunteers negative for anti$H$ pylori antibody at a concentration of $2 \mathrm{x}$ $10^{6} / \mathrm{ml}$ for 18 hours with $H$ pylori $(15 \mu \mathrm{g} / \mathrm{ml})$ or phytohaemagglutinin $(10 \mu \mathrm{g} / \mathrm{ml})$ plus phorbol myristate acetate $(10 \mathrm{ng} / \mathrm{ml})$ respectively in carbon dioxide independent medium (Gibco) 
containing $100 \mathrm{U} / \mathrm{ml}$ penicillin, $10 \mu \mathrm{g} / \mathrm{ml}$ streptomycin, $20 \mathrm{mM}$ L-glutamine, and $10 \%$ fetal calf serum. After 18 hours stimulation, lymphocytes were washed three times and incubated for a further 48 hours in the medium. Medium at the end of this period was collected and used as cytokine rich supernatants.
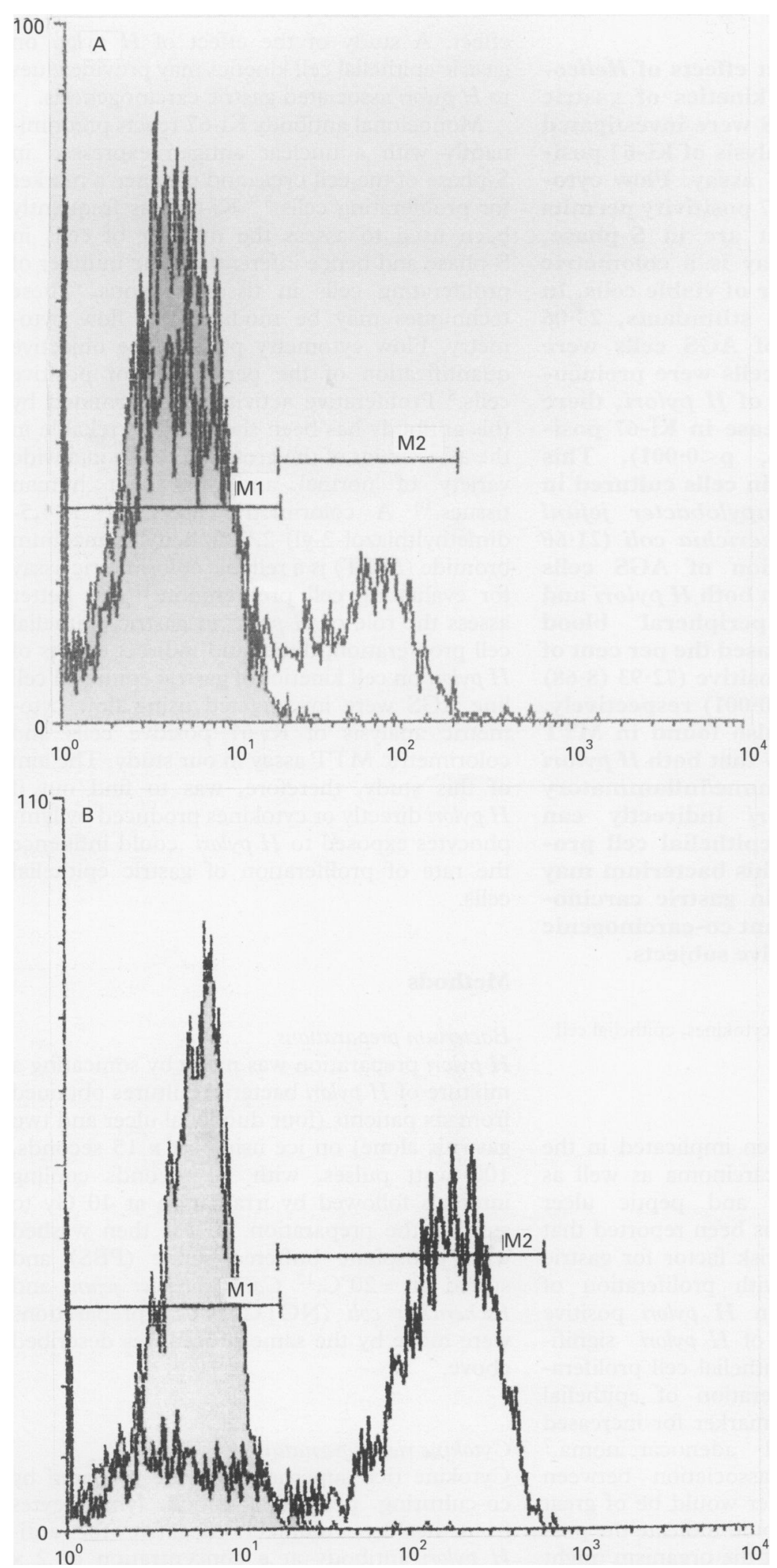

Figure 1: FACScan profiles of Ki-67 positive AGS cells in control $(A)$ and $\mathrm{H}$ pylori groups $(B)$. The shaded histograms represent background and open histograms represent the profiles of Ki-67 positive cells. The marker 2 (M2) outlines the positive cell population and shows that there is a significant increase in Ki-67 positive cells in $\mathrm{H}$ pylori stimulated group $(B)$ than that in control $(A)$.

\section{Epithelial cell culture}

A gastric epithelial cell line (ATCC), AGS, derived from a human gastric adenocarcinoma was used in the study. ${ }^{13}$ AGS cells were cultured as monolayer in Ham F12 medium supplemented with $100 \mathrm{U} / \mathrm{ml}$ penicillin, 100 $\mu \mathrm{g} / \mathrm{ml}$ streptomycin, $20 \mathrm{mM}$ L-glutamine, and $10 \%$ fetal calf serum in flasks at $37^{\circ} \mathrm{C}$ in a humidified atmosphere of $5 \%$ carbon dioxide in air.

\section{Ki-67 labelling}

AGS cells removed from flasks by trypsin treatment were seeded into 8 well culture plates at a concentration of $10^{5}$ cells per well. When the cells were grown to subconfluency, the cells were incubated for a further 24 hours with medium alone, $H$ pylori $(15 \mu \mathrm{g} / \mathrm{ml})$, and cytokine rich supernatants $(0.5 \mathrm{ml} / \mathrm{ml})$ from both $H$ pylori and mitogen activated lymphocytes respectively. As bacterial control, AGS was also co-cultured with $C$ jejuni and $E$ coli respectively with the same procedures and concentrations as $H$ pylori. After co-culture with bacteria or supernatants, the cells were removed from plates by trypsin treatment and resuspended in fresh medium, and labelled using monoclonal antibody Ki-67 (Dakopatts, Denmark) in a series of steps. ${ }^{8}$ Some $200 \mu l$ lysis-DNA-staining solution (calcium and magnesium free Hanks's balanced salt solution, Nonidet P-40 (0.5\% v/v), RNase $0.2 \mathrm{mg} / \mathrm{ml}$, EDTA $0.5 \mathrm{mM}, \mathrm{pH} 7.2$ ) were added to the appropriate cell suspension tubes and shaken for 15 minutes in ice. Ki-67 antibody (diluted in 1:25 in PBS with $1 \%$ bovine serum albumin) was added and incubated for 15 minutes in ice, then $100 \mu l$ of fluorescein-conjugated rabbit antimouse (Fab')2 fragments was added and incubated for a further 15 minutes in ice. An irrelevant antibody (anti-murine IE) was used as control. The cells were analysed by flow cytometry immediately.

\section{MTT assay}

Briefly, $100 \mu \mathrm{l}$ containing $1 \times 10^{5} \mathrm{cells} / \mathrm{ml}$ trypsinised AGS cells were seeded into each well of the 96 well plates and incubated at $37^{\circ} \mathrm{C}$ for 24 hours. The cells were then incubated with medium alone or $H$ pylori or cytokine rich supernatants in duplicate at the same concentration as $\mathrm{Ki}-67$ experiment. After a further 48 hours in culture, $10 \mu$ of MTT ( $6 \mathrm{mg} / \mathrm{ml}$, Sigma) was added to each well and incubated again for four hours at $37^{\circ} \mathrm{C}$. MTT was then removed and $200 \mu l$ of dimethylsulphoxide added to each well. The absorbance at $570 \mathrm{~nm}$ was determined using an ELISA reader. ${ }^{11}$

\section{Flow cytometric analysis}

AGS cells stained with $\mathrm{Ki}-67$ were analysed using the Becton Dickinson FACScan and Lysis II software. The percentage of positive cells for $\mathrm{K}-67$ was estimated from the gate accumulated histograms. 


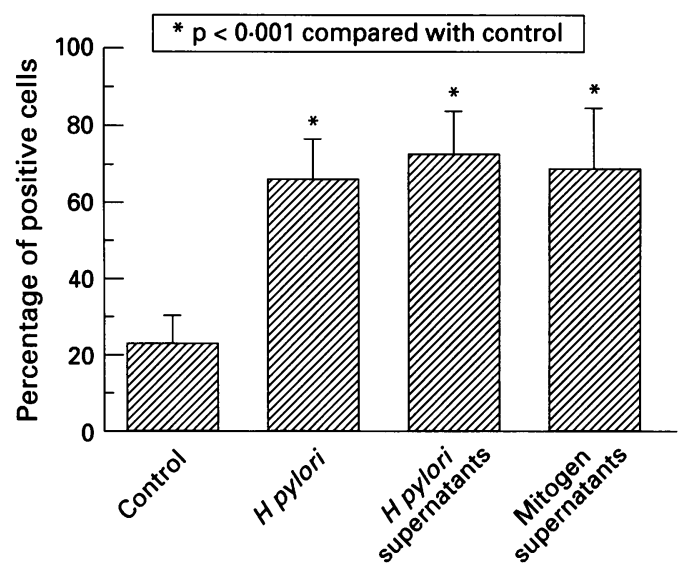

Figure 2: Comparison of Ki-67 positive cells between the control and $\mathrm{H}$ pylori or cytokine rich supernatant stimulated groups. The data are presented as percentage of Ki-67 positive cells. Note that there is a significantly increased proliferative rate of epithelial cell line AGS in $\mathrm{H}$ pylori and cytokine rich supernatant stimulated groups. $\mathrm{H}$ pylori supernatants or mitogen supernatants: supernatants from $\mathrm{H}$ pylori or mitogen activated lymphocytes respectively. $n=6$ determinants for each group.

\section{Statistical analysis}

The significance of the difference between control group and each experimental group was evaluated using Mann-Whitney $U$ test and data were expressed as a mean (SD). Results were expressed as percentage of $\mathrm{Ki}-67$ positive cells in flow cytometry and as optical density (OD) value in MTT assay.

\section{Results}

Flow cytometry

Figure 1 shows FACScan profiles of a representative experiment. As can be seen in Fig 1 non-specific background staining of AGS cells was low (shaded histogram), the marker 2 (M2) shows that there is a significant increase in $\mathrm{Ki}-67$ positive cells in $H$ pylori stimulated group (B) than that in control (A). In the absence of added bacteria or cytokine rich supernatants, $23.06(4 \cdot 88) \%$ of AGS cells were $\mathrm{Ki}-67$ positive. When cells were pre-incubated in the presence of $H$ pylori, there was a significant increase in $\mathrm{Ki}-67$ positivity $(66 \cdot 20$ $(7 \cdot 89) \%$ ) (Fig $1 \mathrm{~B}$ and Fig 2). Pre-incubation

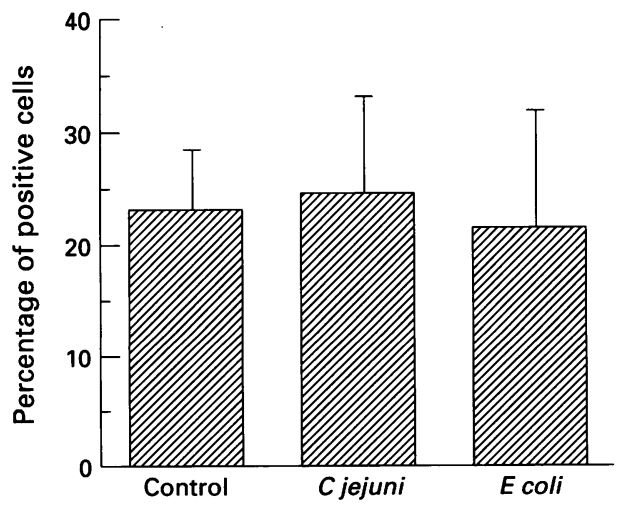

Figure 3: Comparison of Ki-67 positive cells between the control and $\mathrm{C}$ jejuni or $\mathrm{E}$ coli stimulated groups. The results are presented as percentage of Ki-67 positive cells.

Percentage of Ki-67 positive cells does not show significant difference between the control and $\mathrm{C}$ jejuni or $\mathrm{E}$ coli stimulated groups. $n=6$ determinants for each group.
Effects of the different stimulants on cell proliferation of $A G S$ (MTT assay results)

\begin{tabular}{lll}
\hline Stimulants & OD values & $p$ Values* \\
\hline Control & $0.486(0.058)$ & \\
H pylori & $0.632(0.121)$ & $<0.05$ \\
H pylori supernatants & $0.624(0.124)$ & $<0.05$ \\
Mitogen supernatants & $0.616(0.111)$ & $<0.05$
\end{tabular}

*Compared with control. $H$ pylori supernatants or mitogen supernatants: supernatants from $H$ pylori or mitogen activated peripheral blood lymphocytes. $n=6$ determinants for each group. Data shown as mean (SD).

of AGS cells with supernatants from both $H$ pylori and mitogen activated peripheral blood lymphocytes also increased the per cent of the cells that were $\mathrm{Ki}-67$ positive $(72.93$ $(8.68)$ and $69.86(12.36) \%)$ respectively (Fig 2). This increase was not seen, however, in the cells cultured in the presence of $C$ jejun $i$ $(24.63(8.11) \%)$ or $E$ coli $(21.66(9.78) \%)$ (Fig 3).

\section{MTT assay}

Similar results were also seen on AGS cell proliferation using the MTT assay. The OD value reflects increasing cell numbers using this assay. A significant increased $O D$ value was found in $H$ pylori or cytokine rich supernatant stimulated group when compared with control, indicating an increase in cell numbers (Table).

\section{Discussion}

Gastric carcinoma develops through a sequence of events from normal mucosa to gastric carcinoma. $\mathrm{H}$ pylori infection has been thought, based on the epidemiological data and clinical investigations, to be closely associated with this sequence. ${ }^{314}$ Increased proliferation of gastric epithelial cells has been seen in patients with $H$ pylori gastritis. ${ }^{4615}$ These studies have used measurement of bromodeoxyuridine incorporation into cell nucleus on tissue sections. ${ }^{615}$ Bromodeoxyuridine incorporation also represents the number of cells in $S$-phase and hence inferentially the proliferating rate of gastric epithelial cells. These data suggest the $H$ pylori either directly or indirectly may influence the rate of proliferation of gastric epithelium. However, the direct experimental evidence on $H$ pylori stimulated proliferation of epithelial cells is lacking. Our results showed that both $H$ pylori itself and cytokine rich supernatants derived from peripheral blood lymphocytes can significantly increase the proliferative rate of the gastric epithelial cell line AGS. This change in cell proliferation provides suggestive evidence that this bacterium may be an initiating step in increased epithelial cell proliferation and hence potentially gastric carcinogenesis.

A number of studies have shown that $H$ pylori can stimulate peripheral blood lymphocytes to produce various cytokines, including tumour necrosis factor and interferon $\gamma,{ }^{16-18}$ both of which may influence epithelial cell proliferation. ${ }^{19-21}$ Several reports have also shown that $T$ cell mediated response may induce epithelial cell proliferation. ${ }^{22}{ }^{23}$ Factors 
produced by activated $T$ cells including granulocyte-macrophage colony stimulating factor have also been shown to affect the proliferative rate of a colonic epithelial cell line. ${ }^{24}$ Hence, it is not surprising that $\mathrm{T}$ cell derived cytokines may influence epithelial cell proliferation. Our data suggest, however, that antigen specific lymphocyte activation may induce factors that affect gastric epithelial cell proliferation. High rates of local cytokine production have been shown in $H$ pylori infection. ${ }^{1825}$ Hence, it is reasonable to speculate that this may result in increased gastric epithelial proliferation.

There is already preliminary evidence that $H$ pylori itself may directly influence epithelial cell proliferation. Bode and his colleagues showed that $H$ pylori stimulates proliferation of Morris hepatoma cells, ${ }^{26}$ but a direct effect of $H$ pylori on proliferation of an epithelial cell line has not previously been reported. This effect seems to be a specific response to $H$ pylori because no effect of $C$ jejuni or $E$ coli on cell proliferation was found simultaneously. The precise mechanisms for this are unclear at present. Intriguingly, a novel cell proliferation associated gene (pag) has been shown to share approximately $50 \%$ identity with a $26-\mathrm{KDa}$ antigen of $H$ pylori. ${ }^{27}$ Further studies will be required to determine which protein or factor of $H$ pylori may be responsible for the proliferation of epithelial cell line AGS.

We can preliminarily conclude from this study that both $H$ pylori directly and $H$ pylori induced cytokines indirectly can stimulate proliferation of gastric epithelial cell line AGS. This may be of importance in clarifying the role of $H$ pylori in gastric carcinogenesis. The use of this flow cytometric methodology could provide a tool for further more detailed analysis of the role of $H$ pylori in epithelial cell proliferation.

Dr D K is a Wellcome Senior Fellow in Clinical Science.

We wish to thank Professor C J Smyth of the Department of Microbiology, Trinity College for kindly providing $E$ coli.

1 Blaser MJ. Hypothesis on the pathogenesis and natural history of Helicobacter pylori-induced inflammation. Gastroenterology 1992; 102: 720-7.

2 Moss S, Calam J. Helicobacter pylori and peptic ulcers: the present position. Gut 1992; 33: 289-92

3 Parsonnet J, Friedman GF, Vandersteen DP, Chang Y, Vogelman JH, Overtreich N, et al. Helicobacter pylori infection and the risk of gastric carcinoma. $N$ Engl $\mathscr{f} M e d$ infection and the risk

1992; 325: 1127-3.
4 Brenes F, Correa P, Hunter F, Rhamakrishnan T, Fontham E, Shi TY. Helicobacter pylori causes hyperproliferation of the gastric epithelium: pre- and post-eradication indices of proliferating cell nuclear antigen. Am $\mathcal{f}$ Gastroenterol 1993; 88: 1870-5.

5 Tsujii M, Kawano S, Tsuji S, Ito T, Nagano K, Sasaki Y, et al. Cell kinetics of mucosal atrophy in rat stomach induced by long-term administration of ammonia. Gastroenterology 1993; 104: 796-801.

6 Cahill RJ, Sant S, Beattie S, Hamilton H, O'Morain CA.
Helicobacter pylori and increased epithelial cell proliferation: a risk factor for cancer. Eur $\mathcal{f}$ Gastroenterol Hepatol 1994; 6: 1123-7.

7 Lipkin M. Biomarkers of increased susceptibility to gastrointestinal cancer: new applications to studies of cancer prevention in human subjects. Cancer Res 1988; 48: 235-45.

8 Baisch $\mathrm{H}$, Gerdes J. Identification of proliferating cells by Ki-67 antibody. In: Darzynkiewicz S, Crissman HA, eds. Flow cytometry. San Diego, California. Academic Press 1990: 217-26.

9 Gerdes J, Li L, Schluter C, Duchrow M, Wohlenberg C, Gerlach C, et al. Immunobiochemical and molecular biologic characterisation of the cell proliferation associated nuclear antigen that is defined by monoclonal antibody Ki-67. Am ¥Pathol 1991; 138: 867-73.

10 Swanson SA, Brooks JJ. Proliferation markers Ki-67 and P105 in soft-tissue lesions. Am f Pathol 1990; 137 1491-50.

11 Mosmann T. Rapid colorimetric assay for cellular growth and survival: application to proliferation and cytotoxicity assays. F Immunol Methods 1983; 65: 55-63.

12 Brennan DP, Keeling PWN. Campylobacter pylori released membrane-associated and soluble antigens during infection. In: Megraud F, et al eds. Gastroduodenal pathology. and campylobacter pylori. Amsterdam: Elsevier, 1989. 207-11.

13 Barranco SC, Townsend CM Jr, Casartelli C, Macik BG Burger NL, Boerwinkle WR, et al. Establishment and characterisation of an in vitro model system for human adenocarcinoma of the stomach. Cancer Res 1983; 43. 1703-9.

14 Forman D, Eurogast Study Group. An international association between Helicobacter pylori infection and gastric cancer. Lancet 1993; 341: 1359-62.

15 Lynch DFA, Mapstone NP, Clarke AMT, Jackson P, Dixon MF, Quirke $\mathrm{P}$, et al. Cell proliferation in the gastric corpus in Helicobacter pylori associated gastritis and the postsurgical stomach. Gut 1994; 35 (suppl 2): S34.

16 Karttunen R. Blood lymphocyte proliferation, cytokine secretion and appearance of $T$ cells with activation surface markers in cultures with Helicobacter pylori. Comparison markers in cultures with Helicobacter pylori. Comparison of the responses of subjects with and without ant

17 Fan XJ, Chua A, O'Connell M, Kelleher D, Keeling PWN Interferon-gamma and tumour necrosis factor production in patients with Helicobacter pylori infection. Ir $\mathcal{F} \mathrm{Med} S \mathrm{C}$ 1993; 162: 408-11.

18 Fan XJ, Chua A, Shahi CN, McDevitt J, Keeling PWN, Kelleher D. Gastric $T$ lymphocyte responses to Helicobacter pylori in patients with $\mathrm{H}$ pylori colonisation. Gut 1994; 35: 1379-84.

19 Mowat AM, Felstein MV, Parrott DMV. Role of interferons in immunologically mediated enteropathy. Gut $1988 ; 29$, A1436.

20 Mowat AM. Antibodies to IFN-gamma prevent immunologically mediated intestinal damage in graft versus host

21 Ip MM, Shaemaker SF, Daroy KM. Regulation of rat mammary epithelial cell proliferation and differentiation by tumor necrosis factor-alpha. Endocrinology 1992; 130 2833-44.

22 Ferreira RC, Forsyth LE, Richman PI, Wells C, Spencer J, MacDonald TT. Changes in the rate of crypt epithelia cell proliferation and mucosal morphology induced by a T-cell-mediated response in human small intestine. Gastroenterology 1990; 98: 1255-63.

23 Evans CM, Phillips AD, Walker-Smith JA, MacDonald TT. Activation of lamina propria $T$ cells induces crypt epithelial proliferation and goblet cell depletion in cultured human fetal colon. Gut 1992; 33: 230-5.

24 Lowes JR, Priddle JD, Jewell DP. Production of epithelia cell growth factors by lamina propria mononuclear cells. Gut 1992; 33: 39-43.

25 Fan XG, Chua A, Fan XJ, Keeling PWN. Increased gastric production of interleukin-8 and tumour necrosis factor in patients with Helicobacter pylori infection. $\mathcal{f}$ Clin Pathol 1995; 48: 133-6.

26 Bode G, Vergani G. Helicobacter pylori stimulates proliferation of Morris hepatoma (MH1C1 7795) cells. Acta Gastroenterolog Belg 1993; 56: S69.

27 Prosperi MT, Ferbus D, Karczinski I, Goubin G. A human cDNA corresponding to a gene overexpressed during cell proliferation encodes a product sharing homology with amoebic and bacterial proteins. $\mathcal{f}$ Biol Chem 1993; 268: 11050-6. 